\title{
2 Effect of vibration frequency on agonist and antagonist arm 3 muscle activity
}

4 Sergio Rodríguez-Jiménez • Adolfo Benítez •

5 Miguel Ángel García González · Gerard Moras Feliu •

6 Nicola A. Maffiuletti

7 Received: 10 October 2014 / Accepted: 11 January 2015

8 (C) Springer-Verlag Berlin Heidelberg 2015

9 Abstract

10 Switzerland

\begin{abstract}
Purpose This study aimed to assess the effect of vibration frequency $\left(f_{\text {out }}\right)$ on the electromyographic (EMG) activity of the biceps brachii (BB) and triceps brachii (TB) muscles when acting as agonist and antagonist during static exercises with different loads.
\end{abstract}

Methods Fourteen healthy men were asked to hold a vibratory bar as steadily as possible for $10 \mathrm{~s}$ during lying row (pulling) and bench press (pushing) exercise at $f_{\text {out }}$ of 0 (non-vibration condition), 18,31 and $42 \mathrm{~Hz}$ with loads of 20,50 , and $80 \%$ of the maximum sustainable load (MSL). The root mean square of the EMG activity $\left(\mathrm{EMG}_{\mathrm{RMS}}\right)$ of the $\mathrm{BB}$ and $\mathrm{TB}$ muscles was expressed as a function of the maximal $\mathrm{EMG}_{\mathrm{RMS}}$ for respective muscles to characterize agonist activation and antagonist coactivation.

Results We found that (1) agonist activation was greater during vibration $(42 \mathrm{~Hz})$ compared to non-vibration exercise for the TB but not for the BB muscle $(p<0.05)$; (2) antagonist activation was greater during vibration

Communicated by Toshio Moritani.

S. Rodríguez-Jiménez $(\bowtie) \cdot$ A. Benítez · G. M. Feliu Sports Sciences Research Group, INEFC, Institut Nacional d'Educació Física de Catalunya, Centro de Barcelona, University of Barcelona, Avda. de l'Estadi s/n Anella Olímpica de Montjuïc, 08038 Barcelona, Spain

e-mail: sergiorjbcn@gmail.com

A. Benítez · M. Á. G. González

Group of Biomedical and Electronic Instrumentation, Department of Electronic Engineering, Technical University of Catalonia

(UPC), Barcelona, Spain

N. A. Maffiuletti

Neuromuscular Research Laboratory, Schulthess Clinic, Zurich, compared to non-vibration exercise for both $\mathrm{BB}(p<0.01)$ and TB $(p<0.05)$ muscles; (3) the vibration-induced increase in antagonist coactivation was proportional to vibration $f_{\text {out }}$ in the range $18-42 \mathrm{~Hz}$ and (4) the vibrationinduced increase in TB agonist activation and antagonist coactivation occurred at all loading conditions in the range 20-80\% MSL.

Conclusion The use of high vibration frequencies within the range of $18-42 \mathrm{~Hz}$ can maximize TB agonist activation and antagonist activation of both $\mathrm{BB}$ and $\mathrm{TB}$ muscles during upper limb vibration exercise.

Keywords Electromyography $\cdot$ EMG activity . Coactivation $\cdot$ Vibration exercise $\cdot$ Vibratory bar

\section{Abbreviations}

BB Biceps brachii

EMG Electromyography

$f_{\text {out }} \quad$ Vibration frequency

MSL Maximum sustainable load

RMS Root mean square

TB Triceps brachii

WBV Whole body vibration

\section{Introduction}

Vibration exercise is an attractive complement to traditional forms of resistance exercise for athletes, elderly people, and health-compromised individuals (Rittweger 2010). Whole body vibration (WBV) has become the most popular modality of vibration exercise for the lower limbs (Rittweger 2010; Roelants et al. 2006), while several tools like vibratory dumbbells (Bosco et al. 1999), vibrating pulleylike devices (Issurin and Tenenbaum 1999; Mischi and

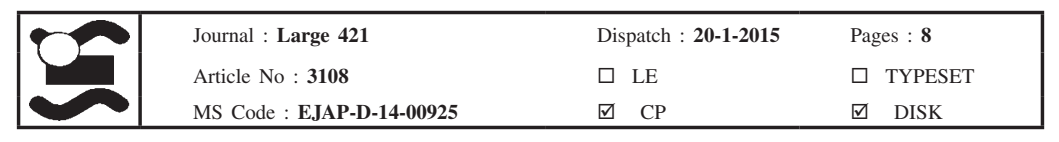


Cardinale 2009) and more recently vibratory bars (Moras et al. 2010; Poston et al. 2007; Rodríguez-Jiménez et al. 2014) have also been specifically designed for upper limb vibration exercise. One of the main features of the vibratory stimulus is that it has been shown to acutely improve specific aspects of neuromuscular performance like maximal power output (Bosco et al. 1999; Cochrane et al. 2008; Issurin and Tenenbaum 1999; Poston et al. 2007), maximal strength (Liebermann and Issurin 1997) and muscle activity, as evaluated with surface electromyography (EMG) (Bosco et al. 1999; Mischi and Cardinale 2009; Moras et al. 2010).

The majority of the studies that focused on the characteristics of the vibration exercise protocol such as vibration frequency, vibration amplitude, body position and load condition (with the objective to define adequate training doses) were conducted on lower limb muscles. In general, WBV exercise resulted in greater EMG activity compared to non-WBV exercise (Cardinale and Lim 2003; Roelants et al. 2006). These studies have used vibration frequencies ranging from 20 to $50 \mathrm{~Hz}$ and submaximal (Hazell et al. 2010; Ritzmann et al. 2013) or maximal loads (Ronnestad et al. 2012). For WBV, there is some evidence suggesting that EMG activity would increase linearly as a function of the vibration frequency within a range of 5-30 Hz (Berschin and Sommer 2004; Pollock et al. 2010; Ritzmann et al. 2013), while inconsistent results were obtained within the 25-50 Hz range (Cardinale and Lim 2003; Hazell et al. 2007, 2010). Similarly to WBV, upper limb vibration exercise in the frequency range $23-31 \mathrm{~Hz}$ has resulted in greater EMG activity of upper limb muscles compared to non-vibration exercise (Bosco et al. 1999; Mischi and Cardinale 2009; Moras et al. 2010). In a recent study evaluating the effects of vibration on arm muscle activity during isometric elbow flexion and extension (Mischi and Cardinale 2009), the vibration-induced $(28 \mathrm{~Hz})$ increase in agonist muscle activity was more evident when higher levels of muscular tension were exerted, while the vibration-induced increase in antagonist coactivation was greater at lower levels of tension. However, until now, no study has systematically compared the impact of different vibration frequencies, including frequencies clearly above $30 \mathrm{~Hz}$, on agonist activation and antagonist coactivation during upper limb vibration exercise with different loads.

Therefore, the aim of the present study was to assess the effect of different vibration frequencies on the EMG activity of the biceps brachii (BB) and triceps brachii (TB) muscles when acting as agonist and antagonist during pulling and pushing static exercises with different loads. The EMG data reported in the present study were collected in our previous work (Rodríguez-Jiménez et al. 2014). Based on the existing literature, we formulated the following hypotheses: (1) vibration exercise would result in greater agonist activation and antagonist coactivation than non-vibration exercise; (2) the expected vibration-induced increase in agonist activation and antagonist coactivation would be proportional to the vibration frequency and (3) would occur regardless of the applied load.

\section{Methods}

Subjects and study design

Fourteen healthy men (mean \pm SD: age $25 \pm 5$ years; height $179 \pm 5 \mathrm{~cm}$; body weight $74 \pm 6 \mathrm{~kg}$ ) volunteered to participate in the study. They had previous experience in supervised resistance training (at least 2 sessions/week during the 2 years preceding the study), but not in vibration exercise. A repeated-measures (single-session) design consisting of 24 randomly-presented measurements was used to analyze the influence of four different vibration frequencies $\left(f_{\text {out }}\right)$ (0 [non-vibration], 18, 31 and $\left.42 \mathrm{~Hz}\right)$ on the EMG activity of the BB and TB muscles during pulling and pushing static exercises with three different loading conditions $(20,50$ and $80 \%$ of the maximum sustainable load [MSL]). For each of the 24 measurements $\left(4 f_{\text {out }} \times 2\right.$ exercises $\times 3$ loads), subjects were asked to hold the vibratory bar as steadily as possible for $10 \mathrm{~s}$ while keeping the elbow joint angle at approximately $90^{\circ}$. The study was conducted in accordance with the Declaration of Helsinki and was approved by the "Comitè d'ètica d'investigacions clíniques de l'Administració esportiva de Catalunya" (01/2011/ CEICEGC). Written informed consent was obtained from all participants before inclusion.

\section{Experimental setup}

For measurements during the lying row (pulling) exercise, subjects lay prone on a horizontal bench elevated over another horizontal bench. For measurements during the bench press (pushing) exercise, subjects lay supine on the lower horizontal bench with their knees flexed approximately $90^{\circ}$. The vibratory bar entails a three-phase electric vibrating motor (Italvibras M3/45-S02, 50 Hz, Fiorano Modenese, Italy) fixed in a cylindrical central body with two bars welded to its lateral sheets. The length and mass of the vibratory bar were $1.1 \mathrm{~m}$ and $8.8 \mathrm{~kg}$, respectively. An-inverter (Omron Sysdrive 3G3JV, single phase $230 \mathrm{~V}, 0.55 \mathrm{~kW}$ ) was used to reduce the speed of the motor (3,000 rpm) according to the required frequency. The two extremities of the vibratory bar were attached to the guide rails of a pneumatic resistance system (Keiser Half Rack, Fresno, CA) by means of carabineers, which allowed pneumatic pulleys to roll seamlessly with the movement of the bar (Rodríguez-Jiménez et al. 2014).

\begin{tabular}{|l|ll|}
\hline Journal : Large 421 & Dispatch : 20-1-2015 & Pages : 8 \\
Article No : $\mathbf{3 1 0 8}$ & $\square$ LE & $\square$ TYPESET \\
MS Code : EJAP-D-14-00925 & $\square \quad C P$ & $\square$ DISK \\
\hline
\end{tabular}




\section{PULLING EXERCISE}

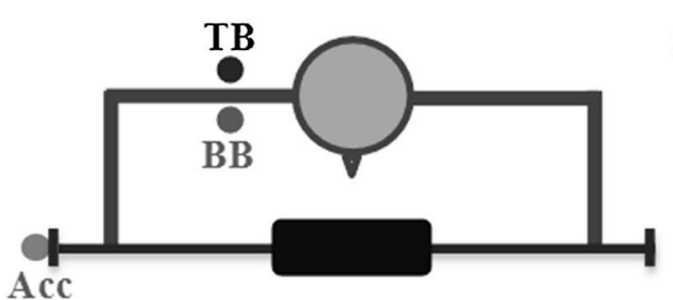

$1000 \mu \mathrm{V}$

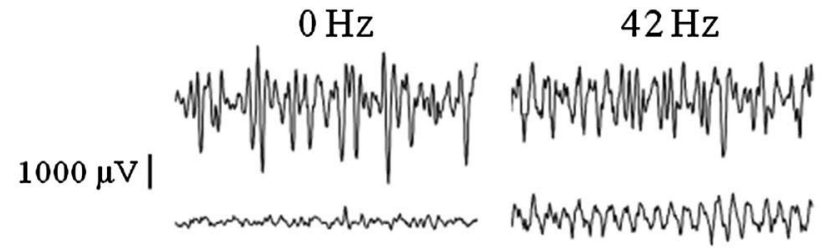

$2 g$

$250 \mathrm{~ms}$
BB EMG

(agonist)

TB EMG

(antagonist)

Acceleration

- $X$-axis

O $Y$-axis

- $Z$-axis
PUSHING EXERCISE

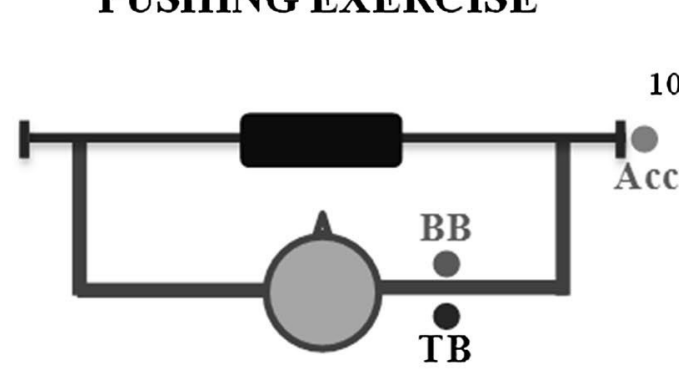

Fig. 1 EMG data of a representative subject with $f_{\text {out }}$ of $0 \mathrm{~Hz}$ (nonvibration) and $42 \mathrm{~Hz}$ and load of $50 \%$ MSL during pulling and pushing exercises. For each exercise, the top shows the EMG data of the

\section{Assessment of MSL}

Subjects were asked to maintain the exercise position as steadily as possible for $5 \mathrm{~s}$, while the $90^{\circ}$-elbow joint angle was verified with an electronic goniometer (SG110, Biometrics Ltd, Newport, United Kingdom). They were asked to hold the vibratory bar with a pronated grip and not to modify the wrist position during the assessments. Previously documented training experience was used as guidance for selecting the initial test weight. The load was progressively increased by $10 \mathrm{~kg}$ after each successful attempt until the subject was unable to maintain the isometric position for at least $5 \mathrm{~s}$. Then, the load was decreased by $5 \mathrm{~kg}$ and a last attempt was made. The load corresponding to the last successful attempt was considered as the MSL (pulling: $86 \pm 8 \mathrm{~kg}$; pushing: $79 \pm 14 \mathrm{~kg}$ ).

\section{Vibration exercise}

Subjects were asked to hold the vibratory bar as steadily as possible for $10 \mathrm{~s}$ with an elbow joint angle of $90^{\circ}$, and with fout of 0 (non-vibration condition), 18,31 and $42 \mathrm{~Hz}$ and loads of 20, 50 and $80 \%$ MSL. The order in which the different frequencies and loads were assigned was randomized biceps brachii (BB) and triceps brachii (TB) muscles. The curves at the bottom illustrate the three-dimensional acceleration of the vibratory bar

between subjects. The duration of recovery phases was self-selected on an individual basis, with a minimum of 3 min between trials and 10 min between the two exercise types (pushing and pulling).

EMG recordings

Surface EMG activity of the right TB (long head) and BB muscles (Fig. 1) was recorded during all maximal (MSL assessment) and submaximal trials. For each muscle, two sensors (inter-electrode distance: $25 \mathrm{~mm}$; Blue Sensor, Medicotest, Ølstykke, Denmark) were placed longitudinally to the orientation of muscle fibers, approximately halfway from the motor point area to the distal part of the muscle (Hermens et al. 2000). The reference electrode was placed 5-6 cm away from the active sensors, as per manufacturer's specifications. Prior to electrode placement, the skin was shaved, abraded and cleaned with isopropyl alcohol to reduce inter-electrode impedance. The cables were carefully taped to the skin to avoid motion artifacts. EMG electrodes were connected to a 14-bit AD converter (ME6000 Biomonitor, Mega Electronics, Kuopio, Finland; sensitivity: $1 \mu \mathrm{V}$, CMRR: $110 \mathrm{~dB}$ ) by pre-amplified cables. Raw EMG signals were pre-amplified (gain: 305,

\begin{tabular}{|l|lll|}
\hline Journal : Large 421 & Dispatch : 20-1-2015 & Pages : 8 \\
Article No : $\mathbf{3 1 0 8}$ & $\square$ LE & $\square$ TYPESET \\
MS Code : EJAP-D-14-00925 & $\square \quad$ CP & $\square \quad$ DISK \\
\hline
\end{tabular}


Table 1 Raw $\mathrm{EMG}_{\mathrm{RMS}}$ data $(\mu \mathrm{V})$ of the biceps brachii (BB) and triceps brachii (TB) by frequency $\left(f_{\text {out }}\right)$ and load conditions

\begin{tabular}{|c|c|c|c|c|c|c|}
\hline \multicolumn{7}{|c|}{ Vibration $f_{\text {out }}$} \\
\hline Exercise & Muscle & Load & $0 \mathrm{~Hz}$ & $18 \mathrm{~Hz}$ & $31 \mathrm{~Hz}$ & $42 \mathrm{~Hz}$ \\
\hline \multirow[t]{6}{*}{ Pulling } & \multirow[t]{3}{*}{$\mathrm{BB}$} & $20 \% \mathrm{MSL}$ & $214 \pm 149$ & $210 \pm 109$ & $223 \pm 114$ & $250 \pm 137$ \\
\hline & & $50 \% \mathrm{MSL}$ & $487 \pm 289$ & $488 \pm 308$ & $457 \pm 275$ & $549 \pm 314$ \\
\hline & & $80 \% \mathrm{MSL}$ & $863 \pm 436$ & $784 \pm 449$ & $789 \pm 453$ & $777 \pm 426$ \\
\hline & \multirow[t]{3}{*}{ TB } & $20 \% \mathrm{MSL}$ & $84 \pm 30$ & $88 \pm 31$ & $108 \pm 36$ & $129 \pm 41$ \\
\hline & & $50 \% \mathrm{MSL}$ & $143 \pm 54$ & $143 \pm 53$ & $180 \pm 76$ & $224 \pm 62$ \\
\hline & & $80 \% \mathrm{MSL}$ & $217 \pm 94$ & $223 \pm 91$ & $266 \pm 118$ & $305 \pm 114$ \\
\hline \multirow[t]{6}{*}{ Pushing } & \multirow[t]{3}{*}{$\mathrm{BB}$} & $20 \% \mathrm{MSL}$ & $34 \pm 15$ & $87 \pm 36$ & $115 \pm 62$ & $134 \pm 75$ \\
\hline & & $50 \% \mathrm{MSL}$ & $76 \pm 50$ & $112 \pm 55$ & $123 \pm 58$ & $172 \pm 91$ \\
\hline & & $80 \% \mathrm{MSL}$ & $92 \pm 46$ & $124 \pm 43$ & $178 \pm 124$ & $226 \pm 123$ \\
\hline & \multirow[t]{3}{*}{$\mathrm{TB}$} & $20 \% \mathrm{MSL}$ & $89 \pm 49$ & $103 \pm 39$ & $116 \pm 54$ & $140 \pm 48$ \\
\hline & & $50 \% \mathrm{MSL}$ & $238 \pm 107$ & $242 \pm 101$ & $267 \pm 112$ & $270 \pm 115$ \\
\hline & & $80 \% \mathrm{MSL}$ & $431 \pm 119$ & $403 \pm 137$ & $414 \pm 168$ & $443 \pm 125$ \\
\hline
\end{tabular}

Mean data \pm SD. MSL maximum sustainable load; $0 \mathrm{~Hz}=$ non-vibration condition
(20, 50 and $80 \%$ MSL) on dependent variables. Effect size statistic, $\eta^{2}$, was analyzed to determine the magnitude of the effect independent of the sample size. The level of significance was set at 0.05 for all the analyses. Data were analyzed using Statistical 7.0 (StataSoft Inc., Tulsa, OK) and are presented as means \pm standard deviations (SD).

\section{Results}

Raw $\mathrm{EMG}_{\mathrm{RMS}}$ values of $\mathrm{BB}$ and $\mathrm{TB}$ muscles by $f_{\text {out }}$ and load conditions are presented in Table 1, for both pulling and pushing exercise.

A significant load effect was consistently observed for all the EMG variables $(p<0.001)$ with a progressive increase in $\mathrm{BB}$ and $\mathrm{TB}$ agonist activation (see also Fig. 2) and antagonist coactivation (see also Fig. 3) with increasing load.

Agonist activation of the BB muscle was not significantly affected by $f_{\text {out }}\left(p=0.18 ; \eta^{2}=0.007\right.$; Fig. $\left.2 \mathrm{a}\right)$. On the other hand, a significant main effect of $f_{\text {out }}(p<0.05$; $\eta^{2}=0.009$ ) was observed for agonist activation of the TB muscle (Fig. 2b). The highest $f_{\text {out }}(42 \mathrm{~Hz})$ elicited a greater $\mathrm{EMG}_{\mathrm{RMS}}$ response than 0 and $18 \mathrm{~Hz}(21 \pm 19 \% ; p<0.05)$.

Antagonist coactivation was significantly affected by $f_{\text {out }}$ for both $\mathrm{BB}\left(p<0.001 ; \eta^{2}=0.278\right.$; Fig. 3a) and TB $\left(p<0.001 ; \eta^{2}=0.058\right.$; Fig. 3b) muscles. For the BB muscle, coactivation was significantly greater at all vibration $f_{\text {out }}$ compared to $0 \mathrm{~Hz}(18 \mathrm{~Hz}: 93 \pm 74 \%$; $31 \mathrm{~Hz}$ : $128 \pm 84 \%$; $42 \mathrm{~Hz}: 172 \pm 84 \%$ ). BB antagonist coactivation was also significantly greater at $42 \mathrm{~Hz}$ than at $18 \mathrm{~Hz}$ $(44 \pm 15 \%)$. For the TB muscle, coactivation was significantly greater at 31 and $42 \mathrm{~Hz}$ compared to both $0 \mathrm{~Hz}$ (29 \pm 4 and $50 \pm 9 \%$, respectively) and $18 \mathrm{~Hz}(24 \pm 2$ and $45 \pm 8 \%$, respectively).

\begin{tabular}{|l|ll|}
\hline Journal : Large 421 & Dispatch : 20-1-2015 & Pages : 8 \\
Article No : 3108 & $\square$ LE & $\square$ TYPESET \\
MS Code : EJAP-D-14-00925 & $\square \quad$ CP & $\square$ DISK \\
\hline
\end{tabular}


Fig. 2 Changes in agonist activation of biceps (a) and triceps brachii (b) muscles by loading $\left(20,50\right.$ and $80 \%$ MSL) and $f_{\text {out }}$ conditions. For each muscle, the top small panel shows the post hoc comparisons for $f_{\text {out }}$ main effect. Values are mean $\pm \mathrm{SD}$, $n=14$. *Significantly higher than $0 \mathrm{~Hz}(p<0.05)$; ¥Significantly higher than $18 \mathrm{~Hz}$ $(p<0.05)$ (a)

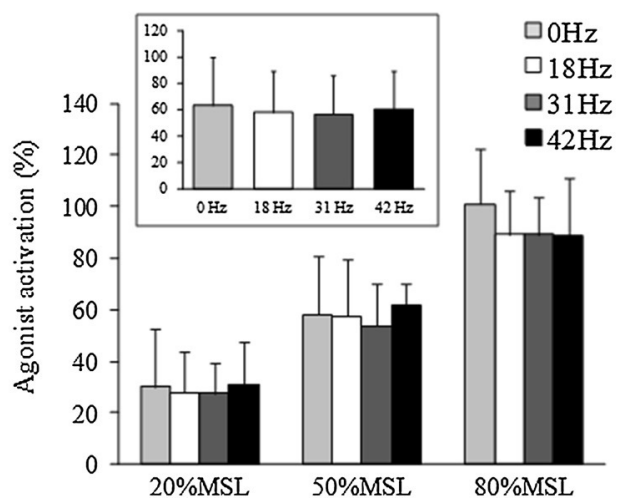

(b) Triceps brachii

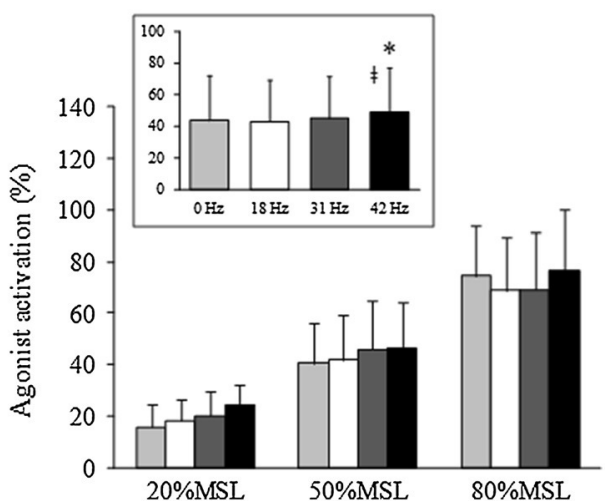

(a)

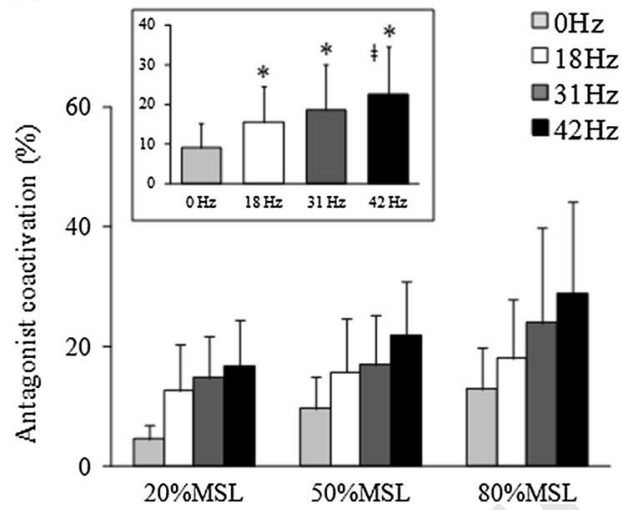

Fig. 3 Changes in antagonist coactivation of biceps (a) and triceps brachii (b) muscles by loading $\left(20,50\right.$ and $80 \%$ MSL) and $f_{\text {out }}$ conditions. For each muscle, the top small panel shows the post hoc comparisons for $f_{\text {out }}$ main effect. Note that the higher the $f_{\text {out }}$ the higher

\section{Discussion}

The main findings of this study were that: (1) agonist activation was greater during vibration exercise at $42 \mathrm{~Hz}$ compared to non-vibration exercise for the TB but not for the BB muscle; (2) antagonist activation was greater during vibration compared to non-vibration exercise for both BB and TB muscles; (3) the vibration-induced increase in antagonist coactivation was proportional to vibration $f_{\text {out }}$ and (4) the vibration-induced increase in TB agonist activation and TB and BB antagonist coactivation was independent from the applied load.

Our first hypothesis was not fully confirmed as vibration exercise at the highest $f_{\text {out }}$ resulted in higher agonist activation than non-vibration exercise for the TB $(+21 \%)$ but not for the BB muscle. A potential explanation for this unexpected discordance between muscles may refer to biomechanical differences between pulling and pushing the vibratory bar. Pulling exercise was mainly characterized by (b)

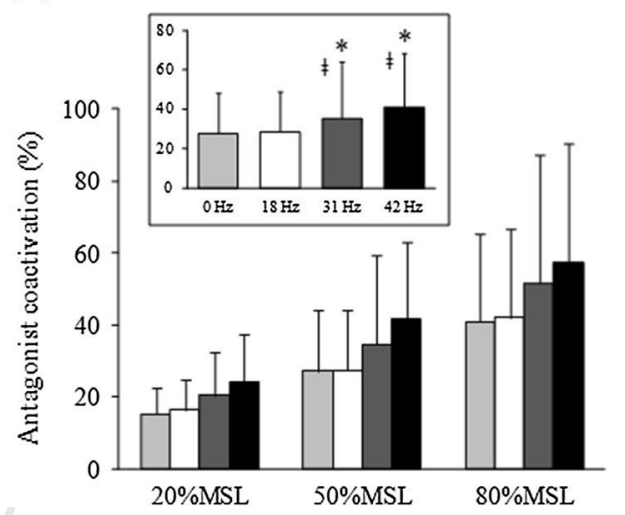

the antagonist coactivation in both muscles. Values are mean $\pm \mathrm{SD}$, $n=14$. a *Significantly higher than $0 \mathrm{~Hz}(p<0.01)$; $\neq$ Significantly higher than $18 \mathrm{~Hz}(p<0.001)$; b $*$ Significantly higher than $0 \mathrm{~Hz}$ $(p<0.05)$; $\neq$ Significantly higher than $18 \mathrm{~Hz}(p<0.05)$

combined grip and pull-only coupling action with the tension acting mainly on the fingers. In contrast, pushing exercise was characterized by combined grip and push with the tension acting mainly at the palm. These differences could have affected in a different way the biodynamic response of the finger-hand-arm system during vibration exposure and the vibration transmissibility to the target muscles (Aldien et al. 2006; Dong et al. 2004, 2005). This leads us to conjecture that the higher effective palm force while pushing the vibratory bar might have favored a larger vibration power transmission to the upper extremity (Dong et al. 2005) compared with pulling, which in turn resulted in greater agonist activation of the TB. However, the observed vibration-induced increase in TB agonist activation was only significant at the higher $f_{\text {out }}$ of $42 \mathrm{~Hz}$. It has been demonstrated that vibration exercise can elicit a stretch reflex response similar to the tonic vibration reflex (Pollock et al. 2012; Ritzmann et al. 2010), which can result in increased motor unit recruitment and/or firing rate (Pollock et al.

\begin{tabular}{|l|lll|}
\hline Journal : Large 421 & Dispatch : 20-1-2015 & Pages : 8 \\
Article No : $\mathbf{3 1 0 8}$ & $\square$ LE & $\square$ TYPESET \\
MS Code : EJAP-D-14-00925 & $\square \quad C P$ & $\square$ DISK \\
\hline
\end{tabular}


2012; Ritzmann et al. 2010). In the same way, it has also been suggested that during vibration exercise the muscle tendon units are stretched in every vibration cycle (Cochrane et al. 2009), which could induce a frequencydependent activation of the muscles spindles that elicit the stretch reflex responses detectable in the EMG signal (Ritzmann et al. 2010). If it is the case, it can be speculated that the observed vibration-induced increase in TB agonist activation at the highest $f_{\text {out }}$ was caused, at least in part, by a greater number of stretch reflex responses compared to lower $f_{\text {out }}$. Previous studies have found greater agonist activation for the TB with vibration frequencies of 23 and $31 \mathrm{~Hz}$ (Moras et al. 2010), for both TB and BB with $28 \mathrm{~Hz}$ (Mischi and Cardinale 2009), and for the BB with $30 \mathrm{~Hz}$ (Bosco et al. 1999) and $50 \mathrm{~Hz}$ (García-Gutiérrez et al. 2014) when compared to non-vibration exercise. The discordances between these previous studies and our present work may be due to differences in several set up aspects like exercise posture, handle coupling actions, elbow joint angle, vibration device, vibration direction and magnitude of vibration acceleration, which could have influenced the level of agonist activation.

Antagonist activation was greater during vibration compared to non-vibration exercise for both $\mathrm{BB}$ and $\mathrm{TB}$ muscles. These findings are in line with previous WBV and upper limb vibration studies (Mischi and Cardinale 2009; Ritzmann et al. 2013). Interestingly, the fact that vibration moderately increased (for TB) or did not affect (for BB) agonist activation, but strongly increased both BB and TB antagonist coactivation leads us to conjecture that one or more of the following mechanisms could have played a role (Rothmuller and Cafarelli 1995): first, driving $\alpha$-motoneurons during vibration may increase excitation of Renshaw cells, which would inhibit Ia inhibitory interneurons, and increase coactivation (Brooks 1986); second, the complexity of the task for controlling force production during vibration could have resulted in greater coactivation since this latter is needed to control precise movements (Smith 1981). In the upper extremity, muscle coactivation has been demonstrated to produce greater movement accuracy and reduced phase lag to external perturbations (Humphrey and Reed 1983). It is also important to note that the vibration-induced increase in antagonist coactivation observed in the present study was greater for the $\mathrm{BB}$ than for the TB ( 130 vs. $40 \%)$. The abovediscussed differences in the hand-handle coupling actions between pulling and pushing exercises could have favored the higher BB coactivation while pushing the vibratory bar. Moreover, and according to the findings of Mischi and Cardinale (2009), both BB and TB seem to be more sensitive to the vibration exposure during static exercises involving elbow extension (such as the present pushing exercise) as compared to elbow flexion. This could occur because our subjects had more difficulties in controlling joint rotation and upper extremity position during pushing exercise in general, hence adopting a neural strategy favoring increased antagonist EMG activity. The difficulty in controlling this exercise position was also accentuated by the fact that the hand-arm system acted like an inverted pendulum during the pushing exercise. That is, whereas a normal pendulum (pulling lying row exercise) is stable when the bar is hanging downwards, an inverted pendulum (pushing bench press exercise) is inherently unstable (kumar et al. 2013). It has been suggested that antagonist coactivation is necessary to aid the ligaments in maintaining joint stability, equalizing the articular surface pressure distribution, and regulating the mechanical impedance of the joint (Baratta et al. 1988). The observed vibration induced-increase of coactivation that was proportional to vibration $f_{\text {out }}$ in the range of $18-42 \mathrm{~Hz}$ is considered to have a positive effect on joint protection and stabilization associated with postural control strategies during vibration exercise (Berschin and Sommer 2004; Mischi and Cardinale 2009).

As expected, the progressive increase of load from 20 to $80 \%$ of the MSL was associated to a proportional increase in agonist and antagonist activity for both muscles. The present results confirm the previously-reported load-dependent enhancement of EMG activity during WBV (Hazell et al. 2010; Ritzmann et al. 2013) and upper limb vibration exercise (Mischi and Cardinale 2009). Accordingly, this suggests that external loading is a prerequisite for maximizing agonist and antagonist muscle recruitment during upper limb vibration exercise. More interestingly, the effect of vibration on TB agonist activation and antagonist coactivation was consistent whatever the load in the range of 20-80\% MSL. This implies that such modulation is not muscle-tension dependent, and that, whatever the applied load, the superimposed vibration can modify the patter of motor unit recruitment with respect to the same exercise with no vibration. However, our present results are contrary to those reported by Mischi and Cardinale (2009). Again, this could be partly explained by differences between vibrating devices in stimulus transmission, resulting in a different vibration damping effect across loads. The acceleration and peak-to-peak displacement of our vibratory bar were hardly influenced by overloading partly because the vibration source was mounted directly onto the bar (Rodríguez-Jiménez et al. 2014). In contrast, the vibration transmissibility of the device used by Mischi and Cardinale (2009) is clearly tension-dependent because the sinusoidal vibrations are produced by an electromagnetic generator and mechanically transmitted to the hands through belts; an excessive damping effect onto the belts during the lower levels of muscular tension could partly explain the absence of vibration effects they observed. On the other hand, our current results are in line with the findings of Moras et al.

\begin{tabular}{l|lll|} 
Journal : Large 421 & Dispatch : 20-1-2015 & Pages : 8 \\
Article No : $\mathbf{3 1 0 8}$ & $\square$ LE & $\square$ TYPESET \\
MS Code : EJAP-D-14-00925 & $\square \quad C P$ & $\square$ DISK \\
\hline
\end{tabular}


(2010) who observed similar vibration-induced increases in TB (agonist activation), deltoid and pectoralis EMG activity with low loads (vibratory bar of $15 \mathrm{~kg}$ ), which is close to the lighter intensity (20\% MSL) used in the present study.

For the first time, we attempted to understand the impact of different vibration frequencies, including frequencies clearly above $30 \mathrm{~Hz}$, on agonist and antagonist muscle activity during upper limb vibration exercise with different loads. The observed effects suggest specific vibrationrelated benefits as an alternative to resistance exercise with no vibration for both strength training and rehabilitation purposes. Moreover, the observed load-independent increases in agonist and antagonist muscle activity mediated by the vibratory stimulus suggest that such approach could be particularly suitable for rehabilitation programs where only low-force contractions could be produced. Based on the present findings, we propose the following recommendations for upper limb vibration exercise: (1) if the aim is to maximize agonist activation, this is possible for the TB (not for the BB) using a frequency of $\sim 42 \mathrm{~Hz}$ and whatever load in the range of $20-80 \%$ MSL; (2) if the aim is to maximize antagonist coactivation, this is possible for both TB and BB muscles using frequencies higher than $30 \mathrm{~Hz}$ and whatever load in the range 20-80\% MSL. Further research is required to demonstrate how (and if) the acute increases in agonist and antagonist EMG activity mediated by the vibratory stimulus could result into chronic neuromuscular and functional adaptations. Additional studies are also required to explore the mechanisms underlying the differences in muscle activity between vibration and non-vibration upper limb exercise, particularly for the antagonist muscles.

A major limitation of the present study is that we did not demonstrate the chronic effects of vibration exercise. However, the observed acute adjustments could have a potential long-term impact on specific neuromuscular features, provided the stimulus is repeated and adequately modulated over time. Another limitation of our study is that the EMG activity was only recorded from two upper limb muscles, while many other muscles of the shoulder, elbow and wrist contributed to the pulling and pushing exercises. Finally, because all measurements were conducted during static exercise, it is unclear whether similar results can also occur during dynamic actions (concentric or eccentric) which are actually more common in strength training.

\section{Conclusions}

This study has demonstrated that upper limb vibration exercise by use of a vibratory bar did not modify BB agonist activation during lying row (pulling) static exercise compared to non-vibration exercise. On the other hand, a vibration frequency of $42 \mathrm{~Hz}$ was able to increase TB agonist activation during bench press (pushing) static exercise. The vibration-induced increase in antagonist coactivation was proportional to the vibration frequency, and was greater for the $\mathrm{BB}$ than for the $\mathrm{TB}$ muscle. Therefore, the use of high vibration frequencies (within the range of 18-42 Hz) regardless of the level of muscular tension is supposed to be the most important prerequisite for optimizing upper limb vibration exercise.

Acknowledgments The authors thank the participants for their time and effort. The authors would also like to thank Raul Cabello for help in data collection during the study. This research was supported by the European Social Fund and the Commission for Universities and Research of the Catalan Government's Department of Innovation, Universities and Enterprises.

\section{Conflict of interest None.}

Ethical standards The experiments comply with the current laws of the country in which they were performed.

\section{References}

Aldien Y, Marcotte P, Rakheja S, Boileau PE (2006) Influence of hand-arm posture on biodynamic response of the human handarm exposed to zh-axis vibration. Int J Ind Ergon 36:45-59

Baratta R, Solomonow M, Zhou BH, Letson D, Chuinard R, D'Ambrosia R (1988) Muscular coactivation. The role of the antagonist musculature in maintaining knee stability. Am J Sports Med 16:113-122

Berschin G, Sommer H-M (2004) Vibration strength training and joint stabilization: EMG based examination of the influence of vibration frequency and posture on muscle activation and co-activation. Dtsch Z Sportmed 55:152-156

Bosco C, Cardinale M, Tsarpela O (1999) Influence of vibration on mechanical power and electromyogram activity in human arm flexor muscles. Eur J Appl Physiol 79:306-311

Brandt A (2011) Noise and vibration analysis: signal analysis and experimental procedures. Wiley, Chichester, United Kingdom

Brooks VB (1986) The neural basis of motor control. Oxford University Press, New York

Cardinale M, Lim J (2003) Electromyography activity of vastus lateralis muscle during whole-body vibrations of different frequencies. J Strength Cond Res 17:621-624

Cochrane DJ, Stannard SR, Walmsely A, Firth EC (2008) The acute effect of vibration exercise on concentric muscular characteristics. J Sci Med Sport 11:527-534

Cochrane DJ, Loram ID, Stannard SR, Rittweger J (2009) Changes in joint angle, muscle-tendon complex length, muscle contractile tissue displacement, and modulation of EMG activity during acute whole-body vibration. Muscle Nerve 40:420-429

Dong RG, Schopper AW, McDowell TW, Welcome DE, Wu JZ, Smutz WP, Warren C, Rakheja S (2004) Vibration energy absorption (VEA) in human fingers-hand-arm system. Med Eng Phys 26:483-492

Dong RG, McDowell TW, Welcome DE (2005) Biodynamic response at the palm of the human hand subjected to a random vibration. Ind Health 43:241-255

\begin{tabular}{|llll|} 
Journal : Large 421 & Dispatch : 20-1-2015 & Pages : 8 \\
Article No : $\mathbf{3 1 0 8}$ & $\square$ LE & $\square$ TYPESET \\
MS Code : EJAP-D-14-00925 & $\square \quad C P$ & $\square$ DISK \\
\hline
\end{tabular}


Farina D, Merletti R, Enoka RM (2004) The extraction of neural strategies from the surface EMG. J Appl Physiol 96:1486-1495

García-Gutiérrez MT, Rhea MR, Marín PJ (2014) A comparison of different vibration exercise techniques on neuromuscular performance. J Musculoskelet Neuronal Interact 14:303-310

Hazell TJ, Jakobi JM, Kenno KA (2007) Skeletal muscle EMG changes during whole body vibration: the influence of frequency and amplitude. Med Sci Sports Exerc 39:S435

Hazell TJ, Kenno KA, Jakobi JM (2010) Evaluation of muscle activity for loaded and unloaded dynamic squats during vertical whole-body vibration. J Strength Cond Res 24:1860-1865

Hermens HJ, Freriks B, Disselhorst-Klug C, Rau G (2000) Development of recommendations for SEMG sensors and sensor placement procedures. J Electromyogr Kinesiol 10:361-374

Humphrey DR, Reed DJ (1983) Separate cortical systems for control of joint movement and joint stiffness: reciprocal activation and coactivation of antagonist muscles. Adv Neurol 39:347-372

Issurin VB, Tenenbaum G (1999) Acute and residual effects of vibratory stimulation on explosive strength in elite and amateur athletes. J Sports Sci 17:177-182

Kumar N, Verma VP, Mulo T, Dey A, Majumdar S (2013) Three degree of freedom control of inverted pendulum by using repulsive magnetic levitation. Int J Recent Trends Eng Tech 8:91-94

Liebermann DG, Issurin V (1997) Effort perception during isotonic muscle contractions with superimposed mechanical vibratory stimulation. J Hum Mov Stud 32:171-186

Mischi M, Cardinale M (2009) The effects of a 28-Hz vibration on arm muscle activity during isometric exercise. Med Sci Sports Exerc 41:645-653

Moras G, Rodríguez-Jiménez S, Tous-Fajardo J, Ranz D, Mujika I (2010) A vibratory bar for upper body: feasibility and acute effects on EMGrms activity. J Strength Cond Res 24:2132-2142

Pollock RD, Woledge RC, Mills KR, Martin FC, Newham DJ (2010) Muscle activity and acceleration during whole body vibration: effect of frequency and amplitude. Clin Biomech 25:840-846
Pollock RD, Woledge RC, Martin FC, Newham DJ (2012) Effects of whole body vibration on motor unit recruitment and threshold. J Appl Physiol 112:388-395

Poston B, Holcomb WR, Guadagnoli MA, Linn LL (2007) The acute effects of mechanical vibration on power output in the bench press. J Strength Cond Res 21:199-203

Rittweger J (2010) Vibration as an exercise modality: how it may work, and what its potential might be. Eur J Appl Physiol 108:877-904

Ritzmann R, Kramer A, Gruber M, Gollhofer A, Taube W (2010) EMG activity during whole body vibration: motion artifacts or stretch reflexes? Eur J Appl Physiol 110:143-151

Ritzmann R, Gollhofer A, Kramer A (2013) The influence of vibration type, frequency, body position and additional load on the neuromuscular activity during whole body vibration. Eur J Appl Physiol 113:1-11

Rodríguez-Jiménez S, Benítez A, García González MA, Feliu GM, Maffiuletti NA (2014) The influence of preset frequency, loading condition, and exercise type on the mechanical behavior of a novel vibratory bar. J Strength Cond Res 28:982-989

Roelants M, Verschueren SMP, Delecluse C, Levin O, Stijnen V (2006) Whole-body-vibration-induced increase in leg muscle activity during different squat exercises. J Strength Cond Res 20:124-129

Ronnestad BR, Holden G, Samnoy LE, Paulsen G (2012) Acute effect of whole-body vibration on power, one-repetition maximum, and muscle activation in power lifters. J Strength Cond Res 26:531-539

Rothmuller C, Cafarelli E (1995) Effect of vibration on antagonist muscle coactivation during progressive fatigue in humans. J Physiol 485(Pt 3):857-864

Smith AM (1981) The coactivation of antagonist muscles. Can J Physiol Pharmacol 59:733-747

\begin{tabular}{|l|lll|}
\hline Journal : Large $\mathbf{4 2 1}$ & Dispatch : 20-1-2015 & Pages : 8 \\
Article No : $\mathbf{3 1 0 8}$ & $\square \quad$ LE & $\square$ TYPESET \\
MS Code : EJAP-D-14-00925 & $\square \quad C P$ & $\square$ & DISK \\
\hline
\end{tabular}

